\title{
Analisis Pemberdayaan Masyarakat Petani Nilam Di Kabupaten Aceh Jaya Terhadap Tingkat Kreativitas, Negosiasi, Dan Pengambilan Keputusan
}

\section{( Analysis Of Community Empowerment Of Nilam Farmers In Aceh Jaya Regency On Creativity, Negotiation, And Decision Making Level )}

\author{
Azra Algifari ${ }^{1}$, Ira Manyamsari $^{1}$, Irfan $_{\text {Zikri }}{ }^{1}$, Elly Susanti ${ }^{1 *}$ \\ ${ }^{1}$ Program Studi Agribisnis , Fakultas Pertanian, Universitas Syiah Kuala \\ "Corresponding author: ellysusanti@unsyiah.ac.id
}

\begin{abstract}
Abstrak. Tanaman nilam (pogosteman patchouli) merupakan tanaman yang wangi dan berdaun halus serta berbatang segi empat. Tanaman ini biasa diambil daun keringnya untuk disuling dan mendapatkan minyaknya yang kemudian digunakan dalam berbagai kegiatan industri mulai dari kosmetik, parfum, sanitari, obat-obatan dan masih banyak lagi. Salah satu masalah yang dihadapi yaitu rendahnya keberdayaan petani nilam di Kabupaten Aceh Jaya. Hal ini disebabkan karena praktik budidaya petani nilam yang masih rendah, kapasitas petani rendah, dan penerapan teknologi yang masih sangat kurang. Penelitian ini dilakukan untuk mengetahui tingkat keberdayaan petani nilam di Kabupaten Aceh Jaya. Berdasarkan hasil penelitian yang dilakukan didapatilah bahwasannya tingkat kreativitas, kemampuan negosiasi, dan kemampuan pengambilan keputusan, masih rendah.
\end{abstract}

Kata kunci : Petani nilam, Aceh Jaya, Pemberdayaan, fujikake.

Abstract. Patchouli (Pogosteman patchouli) is a fragrant plant with smooth leaves and rectangular trunk. This plant is usually taken dry leaves to be distilled and get the oil which is then used in various industrial activities ranging from cosmetics, perfumes, sanitation, medicine and many more. One of the problems faced is the low empowerment of patchouli farmers in Aceh Jaya Regency. This is due to patchouli cultivation practices that are still low, farmer capacity is low, and the application of technology is still very lacking. This research was conducted to determine the level of empowerment of patchouli farmers in Aceh Jaya Regency. Based on the results of the research conducted, it was found that the level of creativity, negotiation ability, and decision-making ability were still low.

Keywords: Patchouli farmer, Aceh Jaya, Empowerment, fujikake.

\section{PENDAHULUAN}

Tanaman nilam (pogosteman patchouli) merupakan tanaman yang wangi dan berdaun halus serta berbatang segi empat. Tanaman ini biasa diambil daun keringnya untuk disuling dan mendapatkan minyaknya yang kemudian digunakan dalam berbagai kegiatan industri mulai dari kosmetik, parfum, sanitari, obat-obatan dan masih banyak lagi. Pada saat ini, permintaan terhadap minyak nilam sangat tinggi karena sifatnya yang fixative terhadap bahan pewangi agar aroma bertahan lama, sehingga dapat mengikat aroma wangi dan mencegah penguapan zat pewangi. Umur tanaman nilam terbilang produktif yaitu selama 1-2 tahun.

Indonesia merupakan pemasok sekitar 85 persen kebutuhan minyak nilam dunia dengan rata-rata volume ekspor 1.057 ton (Manurung 2010). Dari jumlah tersebut kontribusi minyak nilam Aceh hanya sekitar $15-20$ persen. Hal ini jauh menurun dibandingkan dengan kontribusi minyak Aceh Tahun 80-an yang mencapai 80-90 persen dari supply minyak nilam Indonesia. Menurunnya supply minyak nilam Aceh hampir sama dengan kendala umum di wilayah lain di Indonesia antara lain adalah (1) Rendahnya rendemen minyak nilam yang diperoleh, (2) Mutu minyak rendah dan beragam karena pengawasan mutu yang kurang diperhatikan, dan (3) Penyediaan produk tidak kontinyu serta harga yang terjadi berfluktuasi (Yuhono, 2014)

Banyak faktor yang menyebabkan rendahnya rendemen dan kualitas minyak nilam Aceh. Beberapa di antaranya adalah (1) kesulitan memperoleh benih bersertifikat dan bermutu tinggi, (2) ketidakmampuan memprediksi pestisida hayati penyakit nilam (buduk) dan (3) sistem kultur 
transfer. , (4) Sistem pengumpulan babat / tebang ming (panen tunggal), (5) Nilai lokasi kebun tersebar luas, (6) Kualitas kering daun nilam tidak terstandar, (7) Tempat penyimpanan herba tertutup oleh pencemaran tanah dan debu, (8) menggunakan alat destilasi (ketel) tua untuk menghasilkan minyak berkualitas rendah, (9) air yang digunakan untuk menghasilkan uap (uap panas) banyak mengandung polutan, (10) sistem pemasaran cenderung ke arah monopoli atau oligopoli, dan lain-lain.Dalam Laporan BPTP Aceh (2019), menyatakan bahwa sejauh ini pemerintah daerah telah memiliki komitmen yang serius untuk pengembangan produk inovasi klaster nilam melalui Rencana Aksi Sistem Inovasi Industri Nilam Aceh. Tantangan utama dalam pengembangan industri nilam di Aceh Jaya adalah nilai produktivitas dan kualitas produksi nilam yang masih rendah. Hal ini dapat disebabkan oleh skala usaha yang terbatas, rendahnya tingkat pengetahuan petani dan teknologi yang terbatas, kondisi struktur sistem sosial dan peran kelembagaan yang masih rendah.

Permasalahan yang dihadapi produksi minyak nilam adalah ketersediaan bahan baku nilam. Beberapa kabupaten di Kabupaten Aceh Jaya sudah memiliki fasilitas penyulingan minyak nilam, sehingga hanya diperlukan sedikit teknologi tambahan untuk meningkatkan penanaman nilam dan memperoleh produktivitas yang tinggi. Nilam merupakan tanaman penghasil minyak atsiri dan memiliki nilai ekonomi yang sangat baik di pasar luar negeri, mengingat hanya sedikit negara yang memproduksi produk ini, salah satu yang terbesar adalah Indonesia (Cetak Biru Daerah Aceh Jaya, 2017-2021).

Penelitian ini bertujuan untuk mengidentifikasi kinerja pemberdayaan petani nilam di Kabupaten Aceh Jaya dan Mengidentifikasi tingkat keberdayaan petani nilam di Kabupaten Aceh Jaya.

\section{METODE PENELITIAN}

\section{Tempat dan Waktu Penelitian}

Penelitian ini dilakukan di Kabupaten Aceh Jaya, Provinsi Aceh. Lokasi tersebut dipilih karena Aceh Jaya merupakan salah satu wilayah penghasil minyak nilam terbaik dan sampai sekarang terus dikembangkan. Dari 9 Kecamatan dipilih secara sengaja 6 Kecamatan dengan pertimbangan jumlah populasi petani nilam dan luas lahan paling besar. Penelitian ini dilaksanakan pada bulan Januari-Maret 2021.

\section{Objek Penelitian dan Ruang Lingkup Penelitian}

Objek penelitian ini adalah masyarakat klister petani nilam di Aceh Jaya. Ruang lingkup penelitian ini berfokus pada tingkat keberdayaan masyarakat klaster petani nilam yang tersebar di Kabupaten Aceh Jaya.

\section{Populasi dan Sampel}

Dalam penelitian ini populasi yang akan diamati adalah masyarakat petani nilam yang tinggal di kabupaten Aceh Jaya. Pengambilan sampel dilakukan dengan menggunakan metode random sampling, penentuan responden menggunakan rumus Slovin Kusmayadi (2004) menngunakan rumus sebagai berikut:

Ket:

$$
\mathrm{n} \quad=\frac{N}{1+N e^{2}}
$$

$\mathrm{N}=$ Ukuran Sampel

$\mathrm{e}=$ Presisi $10 \%$

$\mathrm{N}=$ Ukuran Populasi 
Dari total 383 orang jumlah total petani nilam yang ada di Kabupaten Aceh Jaya, selanjutnya dengan metode Slovin menggunakan presisi 10\% didapatkan sampel sejumlah 79 orang untuk dijadikan responden yang mewakili populasi Enam Kecamatan yang dipilih yaitu; Panga, Krueng Sabe, Teunom, Sampoinet, Jaya, dan Darul Hikmah. Adapun wilayah Kecamatan Teunom tidak dijadikan lokasi penelitian dikarenakan jarak tempuh yang sangat jauh dan kondisi jalan yang tidak bisa di akses sehingga diganti dengan kecamatan Pasie Raya. Dari penelitian yang telah dilakukan responden yang berhasil dikumpulkan adalah sejumlah 88 petani responden, saat penelitian responden sengaja diambil lebih dari jumlah minimal responden dari metode pemilihan sampel untuk menghindari data kuisioner yang cacat atau hilang.

\section{Teknik Pengumpulan data}

Penelitian ini menggunakan kuisioner, wawancara, dan observasi dalam pengumpulan data, kemudian dengan skala likert akan dilihat subtansi tingkat keberdayaan yang terdiri dari 3 indikator yakni; kreativitas, negosiasi, dan pengambilan keputusan. Kemudian data tersebut diolah dengan analisis deskriptif, lalu dibahas dengan pendekatan kualitatif dengan analisis konteks dan lokalitas dalam mengkaji permasalahan yang ada, selanjutnya merekomendasikan program pemberdayaan dengan intervensi program dan pembelajaran sosial.

\section{Metode Analisis}

Penelitian ini berujuk pada Huberman \& Miles, (2002) dalam menganalisis data, data yang telah diperoleh akan dijelaskan secara deskriptif kualitatif. Adapun teknik yang akan diterapkan antara lain sebagai berikut :

\section{Reduksi dan Cleaning}

Data yang didapatkan di lapangan dalam bentuk catatan peneliti di transformasikan dan dibuat abstrak penelitian. Data yang dianggap penting di kelompokkan untuk selanjutnya menjadi bahan pembuatan laporan. Selanjutnya data yang telah di reduksi di bersihkan dengan melihat kesenjangan data yang dianggap tidak logis kemudian di bersihkan dengan melihat faktor lain dalam kuisioner yang mendukung ke akuratan data tersebut .

\section{Penyajian Data}

Penyajian data berfokus pada penyusunan informasi, kemudian disajikan dalam bentuk naratif, chart, foto, dan peta sosial. Variabel akan dijelaskan dalam tabel persentase jawaban, dan kecendrungan variabel.

Untuk menyusun tabel frekuensi Arnu, Putra and Hasanuh (2020) melakukan analisis data dengan menggunakan teknik proporsional, yaitu melihat persentase jawaban responden dengan langkah-langkah sebagai berikut :

a. Melihat frekuensi jawaban dengan analisis histogram pada aplikasi excel

b. Menyusun frekuensi jawaban

c. Membuat tabel frekuensi

d. Menghitung persentase dari tiap soal dengan rumus sebagai berikut :

\section{Keterangan :}

$$
\mathrm{P}=\frac{\mathrm{F}}{\mathrm{N}} \times 100 \%
$$

$$
\begin{array}{ll}
\mathrm{P} & =\text { Persentase Jawaban } \\
\mathrm{F} & =\text { Frekuensi Pilihan Jawaban Responden } \\
\mathrm{N} & =\text { Jumlah Responden }
\end{array}
$$


Untuk menyusun tabel kecendrungan variabel Sugiyono (2004), mengkategorikan data, lalu disusun berdasarkan mean ideal (Mi) dan standar deviasi ideal (SDi), dengan langkah perhitungan sebagai berikut:
a. $\mathrm{Mi}=\frac{1}{2}$ (skor tertinggi + skor terendah)
b. $\mathrm{SDi}=\frac{1}{6}$ (skor tertinggi - skor terendah)

Selanjutnya Herdjiono, Damanik and Musamus (2016), mengelompokkan variabel menjadi 3 kriteria, pengkategorian variabel dapat dilakukan dengan rumus sebagai berikut:
a. Kategori A ( Tinggi)
$=\mathrm{X} \geq \mathrm{Mi}+\mathrm{SDi}$
b. Kategori B ( Sedang)
c. Kategori C (Rendah)
$=\mathrm{Mi}-\mathrm{SDi} \leq \mathrm{X}<\mathrm{M}+\mathrm{SDi}$
$=\mathrm{X}<\mathrm{M}-\mathrm{SDi}$

Dalam melihat kinerja pemberdayaan dan tingkat keberdayaan masyarakat petani klaster nilam di Aceh Jaya, penelitian ini menggunakan metode penyajian data dengan jaring laba- laba atau radar chart. Data yang akan ditampilkan dalam radar chart adalah nilai index dari indikator yang akan dilihat dengan langkah mencari nilai index sebagai berikut :

- Mendistribusikan frekuensi jawaban responden dalam masing-masing indikator dengan rentang (1-5), nilai 1 tidak baik (positif) dan nilai 5 sangat baik (positif)

- Mencari nilai index dari total skor dalam satu indikator dengan rumus sebagai berikut:

$$
\text { Index } \quad=\frac{\sum(F i 1 \times B \times 1)+\cdots(F i n \times B \times n)}{T B}
$$

Keterangan:

$\mathrm{Fi}=$ Frekuensi jawaban

$\mathrm{Bx}=$ Bobot jawaban

$\mathrm{TB}=$ Total bobot

- Selanjutnya untuk menilai index yang muncul skala 1-5 setiap indikator akan dinilai menjadi 3 kriteria dengan kategori sebagai berikut:

$\begin{array}{ll}\text { Baik } & =>3,67 \\ \text { Kurang Baik } & =2,33-3,67 \\ \text { Tidak Baik } & =3,33-5\end{array}$

\section{HASIL PENELITIAN DAN PEMBAHASAN}

\section{Kreativitas}

Indikator paling lemah yaitu kemampuan melakukan hal baru yang belum dilakukan masyarakat. Poin ini tentu sulit bagi para petani karena mereka tumbuh besar dilingkungn yang sama yang tentunya membuat skill dan kemampuan mereka cenderung sama semuanya. Secara umum masyarakat petani disana masih tergantung dengan alam dan membuat mereka tidak berani berinovasi karena takut dengan kondisi alam yang berubah-ubah. Kehidupan di dalam desa belum terlalu dipengaruhi oleh perubahan-perubahan yang ada disekitarnya, sehingga pola kehidupan disana terkesan statis. Salah satu hal yang membedakan masyarakat desa dengan masayarakat kota/ modern adalah ketergantungan masyarakat desa terhadap kondisi alam dan lingkungannya yang mengakibatkan perbedaan karakteristik antara masyarakat desa dengan kota dalam pola kebudayaannya (Cristiany, 2020). Selain itu, karakteristik sosial masyarakat disana juga cenderung memiliki ritme yang sama antar masyarakatnya. Mereka lebih nyaman melakukan hal yang sama dalam jangka waktu yang lama, hal ini menyebabkan sulitnya timbul suatu inovasi kreasi dari masyarakat setempat. Landis (1943), mengatakan bahwa Kegiatan produktivitas masyarakat yang berorientasi pada alam menjadikan masyarakat hanya menunggu keadaan alamiah lingkungannya, mereka tidak memiliki inovasi yang dapat 
diterapkan untuk memangkas waktu untuk menunjang produktivitasnya sehingga menjadikan mereka lamban.

Tabel 1. Tingkat Kreativitas

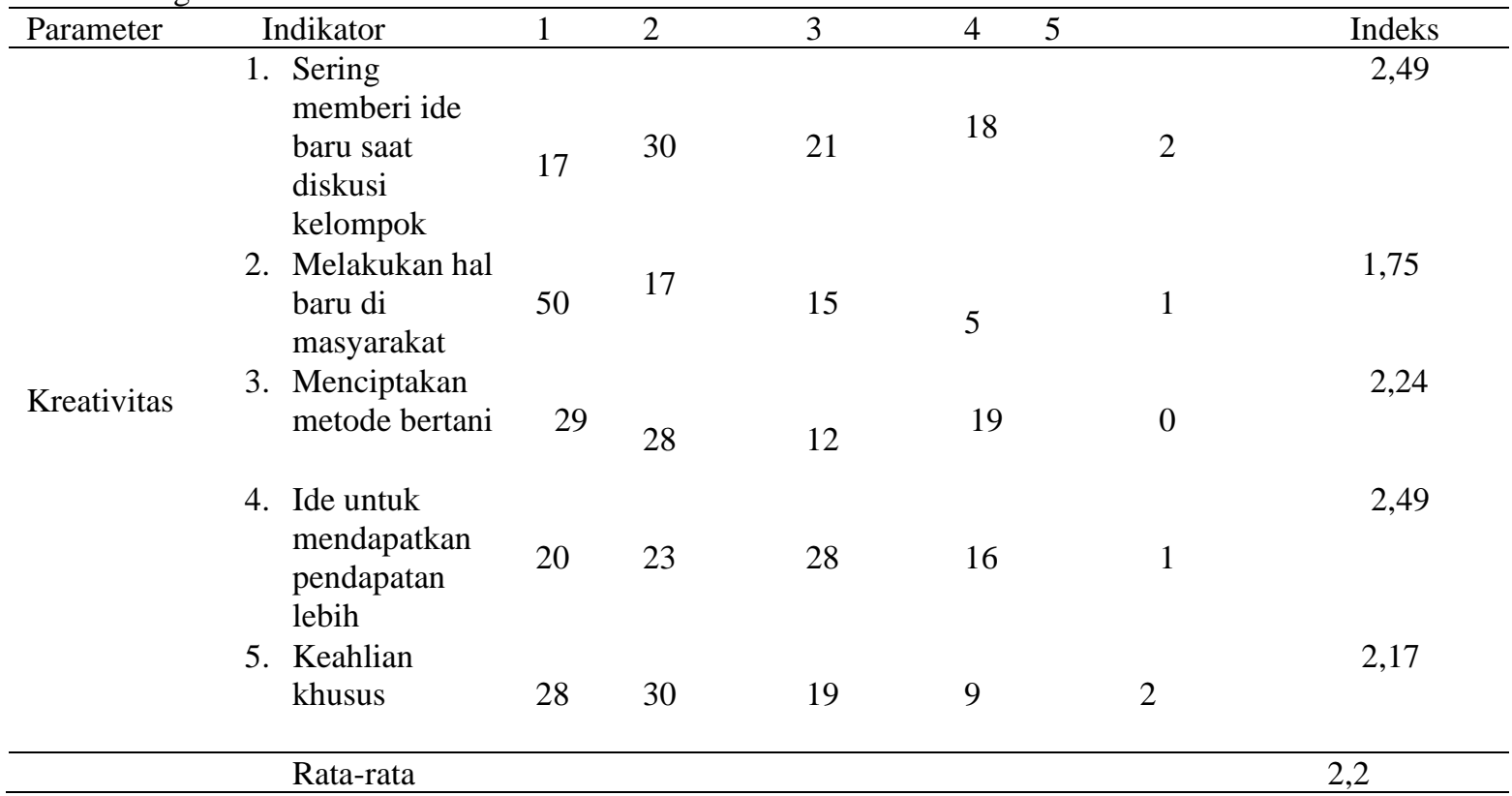

\section{Negosiasi}

Tingkat negosiasi masih lemah. Terdapat 3 indikator yang berkontribusi terhadap lemahnya kemampuan negosiasi bagi para petani.

Tabel 2. Tingkat Kemampuan Negosiasi

\begin{tabular}{|c|c|c|c|c|c|c|c|}
\hline Parameter & Indikator & 1 & 2 & 3 & 4 & 5 & Indeks \\
\hline \multirow{4}{*}{ Negosiasi } & $\begin{array}{l}\text { 1. Kemampuan } \\
\text { meyakinkan } \\
\text { mitra } \\
\text { menawarkan } \\
\text { produk }\end{array}$ & 7 & 31 & 15 & 31 & 4 & 2,93 \\
\hline & $\begin{array}{l}\text { 2. Kemampuan } \\
\text { memperoleh } \\
\text { dukungan } \\
\text { modal usaha } \\
\text { dari pihak lain }\end{array}$ & 42 & 28 & 9 & 9 & 0 & 1,83 \\
\hline & $\begin{array}{l}\text { 3. Kemampuan } \\
\text { memperoleh } \\
\text { dukungan } \\
\text { pendampingan } \\
\text { dari pihak lain }\end{array}$ & 45 & 18 & 13 & 10 & 2 & 1,93 \\
\hline & $\begin{array}{c}\text { 4. Kemampuan } \\
\text { menawarkan } \\
\text { harga dalam } \\
\text { bertransaksi }\end{array}$ & 22 & 24 & 14 & 26 & 2 & 2,57 \\
\hline & Rata-rata & & & & & & 2,3 \\
\hline
\end{tabular}


Pertama yaitu kemampuan memperoleh dukungan modal usaha dari pihak lain, kemudian kemampuan memperoleh dukungan pendampingan dari pihak lain, dan terakhir yaitu Kemampuan menawarkan harga dalam bertransaksi. Mc Guire (2004) mengatakan terdapat tiga faktor utama dalam kemampuan negosiasi yangbaik, yaitu: a. Patience adalah negosiator yang baik menyadari bahwa negosiasi membutuhkan proses, termasuk di dalamnya untuk menghilangkan sekat diantara kedua pihak dan bukan merupakan hasil instan. b. Self confidence, yaitu negosiator yang baik menyadari bahwa dengan memiliki kepercayaan diri berarti memiliki pula keyakinan akan kemampuannya untuk mencapai keberhasilan negosiasi. c. Communicationskill, yaitu negosiator yang baik menyadari bahwa dengan melibatkan dua pihak, negosiasi membutuhkan kemampuan komunikasi yang baik agar mampu menangkap pesan secara efektif. Data dilapangan menjelaskan bahwa para petani menyukai hal yang instan dan cepat, mereka sering tidak sabra untuk menunggu proses sehingga membuat tingkat negosiasi mereka kurang baik. Selain itu, masyarakat petani nilam juga tidak memiliki kepercayaan diri yang tinggi yang berdampak pada rendahnya kemampuan negosiasi.

\section{Pengambilan Keputusan}

Dalam penelitian ini tingkat kemampuan mengambil keputusan masyarakat petani nilam dilihat dari bagaimana tindakan mereka bertindak dalam lingkungan masyarakat maupun dengan stakeholder yang berlaku dan pengetahuan masyarakat dalam kegiatan budidaya tanaman nilam yang selama ini mereka lakukan. Tingkat pengambilan keputusan tentu dibutuhkan oleh petani. Contohnya yaitu petani mampu mengambil keputusan yang beresiko terhadap produksi. Petani diharuskan mampu dan berani mengambil keputusan, karena tentu dalam proses pelaksanaannya akan ada hal-hal mendadak yang memaksa petani untuk menentukan pilihan. Apabila petani terlalu bermain di zona aman maka mereka akan kesulitan saat didalam kondisi harus menentukan pilihan.

Tabel 3. Tingkat Kemampuan Pengambilan Keputusan

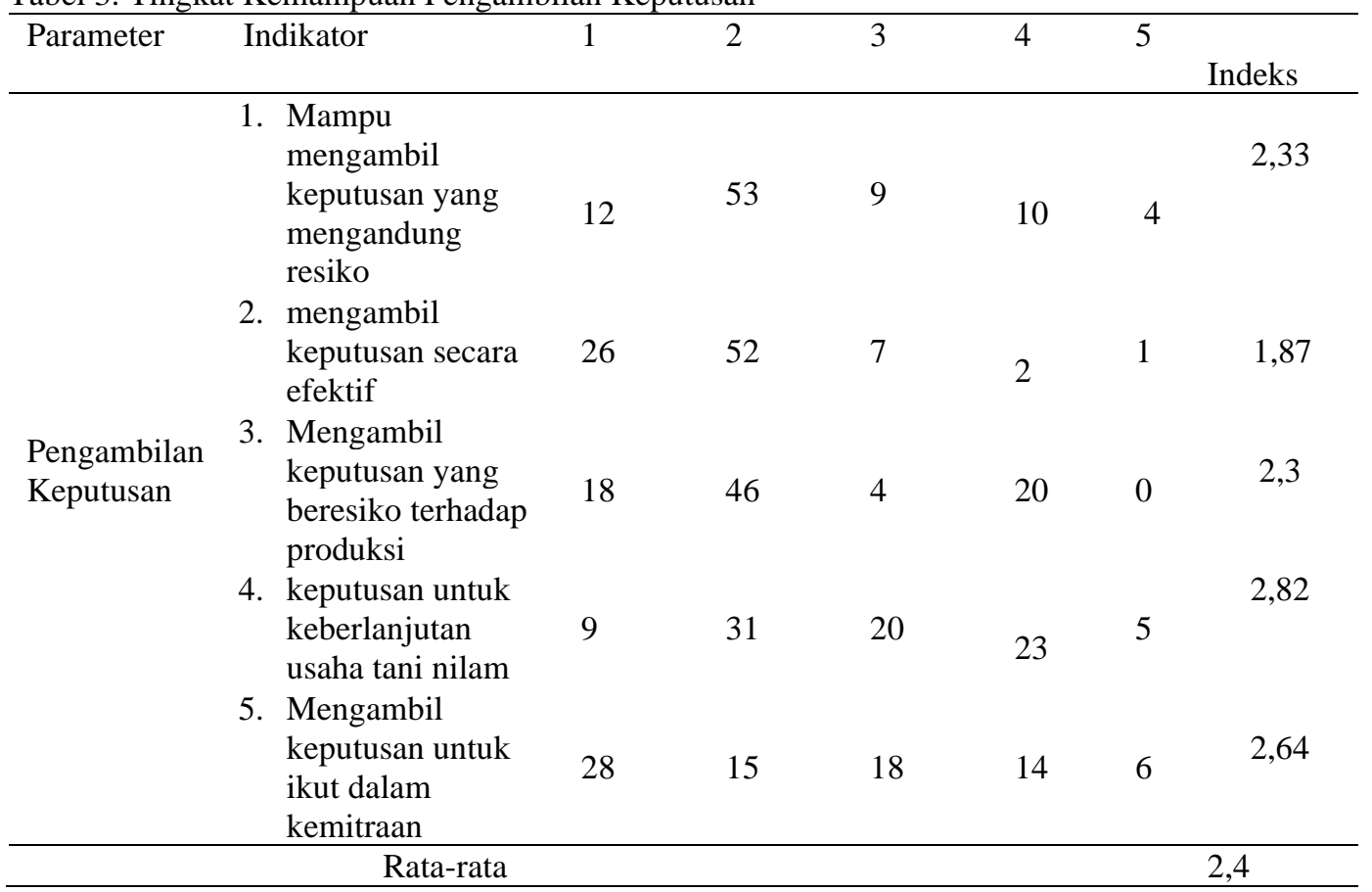

Berdasarkan kriteria interval yang telah ditentukan, nilai indeks untuk variable tingkat pengambilan keputusan yaitu 2,4 dan termasuk dalam kategori kurang baik, maka dapat ditarik 
kesimpulan bahwa tingkat pengambilan keputusan petani nilam masih kurang baik dan butuh perhatian khusus dari pemerintah agar ditingkatkan lagi. Terdapat 3 Indikator paling lemah yang harus diperhatikan dan ditingaktkan yaitu Dapat mengambil keputusan secara efektif dan tepat sasaran, kemudian mampu mengambil keputusan yang mengandung resiko dan terakhir yaitu mengambil keputusan yang beresiko terhadap produksi. Hal ini berhubungan dengan rendahnya kreativitas. Petani tidak berani berinovasi atau mengambil resiko dalam melakukan manajemen usaha. Karakteristik sosial masyarakat yang cenderung bermain aman dan berani melakukan hal baru membuat mereka sulit untuk mengambil keputusan. Poin ini harus menjadi perhatian khusus agar petani dapat lebih pintar dan mampu mengambil keputusan dengan baik guna meningkatkan kualitas budidayanya.

\section{Tingkat Keberdayaan Petani Nilam}

Terdapat 3 indikator yang digunakan dalam penelitian ini untuk melihat dan memahami kinerja pemberdayaan dan tingkat keberdayaan, antara lain kreativitas, kemampuan negosiasi dan pengambilan keputusan. Masing masing indikator ini akan dijadikan acuan untuk melihat permasalahan yang rasakan masyarakat petani nilam dalam kegiatan budidaya nilam seharihari. Dalam melihat masalah yang dihadapi petani nilam, penelitian ini akan menilai dari jawaban reseponden yang telah diberi skor yang selanjutnya dari skor tersebut dicari index skor dari setiap subtansi kinerja keberdayaan, skor 5 dinilai sudah baik, sedangkan subtansi yang memiliki arah skor mendekati 1 dinilai tidak baik dan bermasalah.

Tabel 4. Indeks Keberdayaan

\begin{tabular}{lcc}
\hline Indikator & Indeks & \\
& Dalam 1-5 & Kriteria $\left.^{*}\right)$ \\
\hline Kreativitas & 2,2 & Tidak baik \\
Negosiasi & 2,3 & Tidak baik \\
Pengambilan keputusan & 2,4 & Kurang baik \\
\hline
\end{tabular}

\section{Kesimpulan}

\section{KESIMPULAN DAN SARAN}

Berdasarkan hasil penelitian dan pembahasan maka dapat diambil kesimpulan sebagai berikut:

1. Hasil kinerja pemberdayaan masih rendah. Dilihat dari 3 indikator pemberdayaan, dua diantaranya menunjukkan indeks tidak baik dan satu indeks kurang baik. Alasan rendahnya indikator-indikator tersebut yaitu karena masyarakat petani disana masih tergantung dengan alam dan membuat mereka tidak berani berinovasi karena takut dengan kondisi alam yang berubah-ubah. Sehingga tidak adanya dorongan atau Kemampuan dalam diri mereka untuk melakukan kreativitas, negosiasi dan juga Kemampuan pengambilan keputusan.

2. Dilihat dari kinerja pemberdayaan yang masih rendah, dapat dikatakan bahwa tingkat keberdayaan juga rendah. Hal ini didasari dengan fakta dilapangan yang terjadi yaitu petani masih enggan untuk berinovasi sesuatu yang baru dan tidak adanya keahlian khusus yang dimiliki masyarakat. Kemampuan masyarakat disana cenderung sama semua yaitu berfokus pada kemampuan bertani saja. Masyarakat juga masih belum memiliki jaringan yang luas untuk mengembangkan pemasaran nilamnya. Terbatasnya jaringan informasi membuat tingkat negosiasi mereka tidak berkembang. Selain itu wawasan petani yang terbatas dan ketidak-beranian petani untuk mengambil resiko imbas dari ekonomi yang sulit, membuat petani tidak berani dalam mengambil keputusan. 


\section{Saran}

1. Agar pemerintah maupun para penyuluh pertanian dapat membantu meningkatkan kreativitas para petani dengan cara memberikan pelatihan dan mengedukasi petani secara berkala untuk memunculkan atau meningkatkan kemampuan mereka masing-masing.

2. Agar pemerintah atau penyuluh membantu memberikan bantuan kepada petani sekaligus membimbing mereka melakukan negosiasi yang baik dan menguntungkan. Pemberian bantuan juga diharapkan dapat menjadi dorongan kepada petani agar tertarik dan mau ikut dibimbing.

3. Kepada pemerintah, penyuluh ataupun kepada pihak-pihak yang terlibat langsung untuk membantu pemberdayaan masyarakat, agar dapat mengenal petani lebih dalam dulu sebelum melakukan pemberdayaan dengan tujuan pemberdayaan yang diberikan nantinya langsung tepat sesuai yang dibutuhkan.

\section{DAFTAR PUSTAKA}

Abdulsyani, Sosiologi Skematika, Teori, dan Terapan (Jakarta: PT. Bumi Aksara, 2007). Aceh Jaya \& IPB. (2015). Perencanaan (Blueprint) Percepatan Pembangunan Ekonomi Berbasis Sumberdaya Alam Kabupaten Aceh Jaya Tahun 2017-2021. Calang: Pemerintah Kabupaten Aceh Jaya.

Arnu, A. P., Putra, R. A. K. and Hasanuh, N. (2020) 'Pemetaan Sosial Pada Pengrajin Bambu di Desa Parungsari Kabupaten Karawang', Aksara: Jurnal Ilmu Pendidikan Nonformal, 6(2), p. 139.

Cristiany, J., 2020. Dampak Penggunaan Teknologi Informasi Komunikasi Terhadap Pola Komunikasi Masyarakat Desa. Jurnal Penelitian Komunikasi dan Pembangunan, 21(2), pp. 131-140.

Endah, N., 2017. Modul Sosiologi Pedesaan. Yogyakarta: Universitas Negeri Yogyakarta.

Herdjiono, I., Damanik, L. A. and Musamus, U. (2016) 'Pengaruh Financial Attitude, Financial Knowledge, Parental Income terhadap Financial Management Behavior', (3), pp. 226241

Huberman, A. M., \& Miles, M. B. (2002). The Qualitative Research's Companion. London: Sage Publication.

Kusmayadi. (2004). Statistika Pariwisata Deskriptif. Jakarta: PT. Gramedia Pustaka Utama. Landis, P. H., 1943. Rural Sociology and The Folk Society. Rural Sociology, 8(1).

Nasrun, Y. Nuryani, Hobir, dan Repianyo. 2004. Seleksiketahanan varietas nilam terhadap penyakit layubakteri (Ralstonia solanacearum) secara in planta,Journal Stigma.12(4): 471-473.

Soekanto, S., 2006. Sosiologi Suatu Pengantar. Jakarta: Raja Grafindo Persada.

Sugiyono. (2004). Statistika Untuk Penelitian. Bandung: Alfabeta.

Yuhono, 2014. Strategi Peningkatan Rendemen dan Mutu Minyak dalam Agribisnis Nilam, Balai Penelitian Tanaman Obat dan Aromatik. Bogor, Jawa Barat. 